Article

\title{
Cytotoxic Desulfated Saponin from Holothuria atra Predicted to Have High Binding Affinity to the Oncogenic Kinase PAK1: A Combined In Vitro and In Silico Study
}

\author{
Md Shahinozzaman ${ }^{1,2}$, Takahiro Ishii $1,3, *$ (D) , Ryo Takano ${ }^{3}$, Mohammad A. Halim ${ }^{4}$, \\ Md Amzad Hossain 1,5 and Shinkichi Tawata 2,3,* (iD \\ 1 The United Graduate School of Agricultural Sciences, Kagoshima University, Korimoto 1-21-24, \\ Kagoshima 890-0065, Japan; mshahin81@gmail.com (M.S.); amzad@agr.u-ryukyu.ac.jp (M.A.H.) \\ 2 PAK Research Center, University of the Ryukyus, Okinawa 903-0213, Japan \\ 3 Department of Bioscience and Biotechnology, Faculty of Agriculture, University of the Ryukyus, Senbaru 1, \\ Nishihara-cho, Okinawa 903-0213, Japan; takano@agr.u-ryukyu.ac.jp \\ 4 Division of Computer Aided Drug Design, The Red-Green Research Centre, 218 Elephant Road, \\ Dhaka 1205, Bangladesh; mahalim@grc-bd.org \\ 5 Subtropical Field Science Center, University of the Ryukyus, Senbaru 1, Nishihara-cho, \\ Okinawa 903-0213, Japan \\ * Correspondence: ishiit@agr.u-ryukyu.ac.jp (T.I.); b986097@agr.u-ryukyu.ac.jp (S.T.); \\ Tel.: +81-090-5472-6883 (S.T.)
}

Received: 3 July 2018; Accepted: 23 August 2018; Published: 31 August 2018

\begin{abstract}
Sea cucumbers have long been utilized in foods and Asiatic folk medicines for their nutritive and health benefits. Herein, three sea cucumber species were investigated and Holothuria atra showed the highest cytotoxicity among these. Next, a desulfated saponin, desulfated echinoside B (DEB), was purified from H. atra through bioassay-guided fractionation. LC-ESI-MS (Liquid chromatographyelectrospray ionization mass spectrometry) analysis also showed $H$. atra to be a rich source of saponins. DEB showed cytotoxicity on cancer cells with $\mathrm{IC}_{50}$ values of $0.5-2.5 \mu \mathrm{M}$, and on brine shrimps with an $\mathrm{IC}_{50}$ value of $9.2 \mu \mathrm{M}$. In molecular docking studies, DEB was found to bind strongly with the catalytic domain of PAK1 (p21-activated kinase 1) and it showed binding energy of $-8.2 \mathrm{kcal} / \mathrm{mol}$ compared to binding energy of $-7.7 \mathrm{kcal} / \mathrm{mol}$ for frondoside A (FRA). Both of them bind to the novel allosteric site close to the ATP-binding cleft. Molecular dynamics (MD) simulation demonstrated that DEB can form a more stable complex with PAK1, remaining inside the allosteric binding pocket and forming the maximum number of hydrogen bonds with the surrounding residues. Moreover, important ligand binding residues were found to be less fluctuating in the DEB-PAK1 complex than in the FRA-PAK1 complex throughout MD simulation. Our experimental and computational studies showed that both DEB and FRA can act as natural allosteric PAK1 inhibitors and DEB appeared to be more promising than FRA.
\end{abstract}

Keywords: Holothuria atra; desulfated echinoside B; molecular docking; molecular dynamics; p21-activated kinase 1

\section{Introduction}

Marine resources represent novel reservoirs of biologically active components, and thus are valued as nutritious foods and traditional medicines worldwide [1,2]. In recent decades, many significant bioactive substances have been extracted from marine organisms [3]. Sea cucumbers are an important 
marine organism, which are widely consumed in China and other Asian countries, due to having numerous health benefits [4]. In addition to their good flavor, they are traditionally used to treat many diseases including wounds, eczema, arthritis, hypertension, and impotence [5,6]. Saponins (triterpene glycosides) are thought to be the major ingredient of sea cucumbers, which have been used in drug discovery due to their diverse biological activities. Recent studies have demonstrated that sea cucumber saponins can cause growth arrest of cancerous cells [7], along with their antioxidant, anti-inflammatory, anti-fungal, anti-angiogenesis, anti-tumor, and immunomodulatory effects [8,9]. Our group recently studied a sulfated saponin frondoside A (FRA), extracted from Cucumaria frondosa, and found that it selectively inhibited the major oncogenic kinase PAK1 ( $\mathrm{p}-21$ activated kinase 1), thereby showing significant anti-cancer effects [10]. PAK1 is essential for the development of RAS cancers which represent over $90 \%$ of pancreatic cancer, $50 \%$ of colon cancer and $30 \%$ of lung cancer [11]. It is also involved in generating many other diseases such as viral/bacterial infections, inflammatory diseases (asthma and arthritis), type 2 diabetes, neurofibromatosis, tuberous sclerosis, epilepsy, depression, schizophrenia, autism etc. [12]. Recently, developing PAK1 inhibitors has gained immense interest among researchers and pharmaceutical industries, particularly those involved in cancer drug development [13]. To date, several synthetic PAK1-blockers have been developed; however, none has received FDA approval as a commercial drug due to non-selectivity and toxicity [12]. Hence, we have recently focused our attention on sea cucumbers, with a view to exploring their anti-cancer properties and developing a series of potent PAK1 blocking saponins. In this study, we investigated three sea cucumber species in vitro for cytotoxicity, and further evaluated the binding affinities and interactions of purified saponin with PAK1 through in silico approaches such as molecular docking and molecular dynamics (MD) simulation [14-16]. This combined approach therefore, would be a benchmark for developing better PAK1-inhibiting cancer chemotherapeutics.

\section{Materials and Methods}

\subsection{Cell Culture and Reagents}

Human lung cancer cell line A549, hepatocarcinoma cell line HuH-7, liver cancer cell line HepG2, and murine melanoma cell line B16F10 were maintained in DMEM (Dulbecco's Modified Eagle's Medium, Thermo Fisher Scientific, Waltham, MA, USA) supplemented with 10\% FBS (Fetal Bovine Serum, HyClone, Victoria, Australia) and 1\% penicillin/streptomycin $(10,000 \mathrm{U} / \mathrm{mL}$ and $100 \mu \mathrm{g} / \mathrm{mL})$ at $37{ }^{\circ} \mathrm{C}$ in a humidified atmosphere containing $5 \% \mathrm{CO}_{2}$. 3-(4,5-dimethylthiazol-2-yl)-2,5-diphenyl-tetrazolium bromide (MTT) and FRA were purchased from Sigma-Aldrich (Saint Louis, MO, USA). All other reagents were of analytical grade and were obtained from either Wako Pure Chemical Industries (Osaka, Japan) or Kanto Chemical Co., Inc. (Tokyo, Japan).

\subsection{Collection of Sea Cucumber Species and Their Extraction}

Holothuria atra and Holothuria leucospilota (Figure 1A,B) were collected by diving on the coast of the Pacific Ocean near Uruma city, Okinawa, Japan. Parastichopus nigripunctatus (Figure 1C) was were collected from the coastal areas of Mie prefecture, Japan. They were carefully dissected carefully to collect the body walls which were then dried at $50{ }^{\circ} \mathrm{C}$ for 4 days. Dried body walls (100 gm) were ground to make a powder which was soaked in $1000 \mathrm{~mL} \mathrm{70 \%} \mathrm{ethanol} \mathrm{(EtOH)} \mathrm{for} 72 \mathrm{~h}$. Then, the supernatant was collected through vacuum filtration, and the remaining powder was again soaked in $70 \% \mathrm{EtOH}$ for the next $72 \mathrm{~h}$. Extraction was done thrice and combined. Hot water extraction was done by soaking the powder in boiling water for $1 \mathrm{~h}$. The hot water supernatant was collected through vacuum filtration. Both the extractions were dried under reduced pressure using rotavapor (Buchi, Switzerland). 


\subsection{Extraction of Crude Saponin and Its Fractionation}

The 70\% EtOH extract of each species was further partitioned between water and chloroform, and the aqueous layer was extracted with $n$-butanol. The organic layer was evaporated to yield $n$-butanol extract which was then concentrated and dissolved in water and chromatographed with reversed-phase $\mathrm{C} 18$ silica gel, using water-methanol gradient elution to yield several fractions. The fraction eluted with $100 \%$ methanol is referred as crude saponin [17-19]. Crude saponin of $H$. atra was further fractionated with high performance liquid chromatography (HPLC, Shimadzu, Kyoto, Japan). The HPLC conditions were as follows: column- semipreparative reversed phase column Luna 5 u C18 $(10 \times 250 \mathrm{~mm})$; solvent A-0.1\% ammonium acetate $(1 \mathrm{M})$; solvent B-acetonitrile $+0.1 \%$ ammonium acetate $(1 \mathrm{M})$; flow rate-3.0 mL/min; absorbance-200 $\mathrm{nm}$. The elution was performed with $60 \%$ solvent B for $45 \mathrm{~min}$. Fr 4 was identified as a pure saponin, desulfated echinoside B (DEB) (Figure 2A), and the retention time for DEB was $20 \mathrm{~min}$. Its structure was determined based on ${ }^{1} \mathrm{H}$, ${ }^{13}$ C NMR and ESI-MS (electrospray ionization mass spectrometry) spectral data and by comparison with those previously reported in the literature [20,21]. In addition, GC (gas chromatography) and GCMS (gas chromatography mass spectrometry) analyses of trimethylsilyl (TMS) and 2-octyl-glycoside derivatives from DEB further confirmed that the sugar moiety consists of D-xylose and D-quinovose.

Desulfated echinoside B (DEB): white solid; $[\alpha]_{\mathrm{D}}^{24}-15.4$ (c 0.1, pyridine). ESI-MS $m / z 789.6[\mathrm{M}+\mathrm{Na}]^{+}$ (calcd. for $\left.\mathrm{C}_{41} \mathrm{H}_{66} \mathrm{O}_{13} \mathrm{Na}, 789.4401\right) .{ }^{1} \mathrm{H} \mathrm{NMR}$ (pyridine- $\left.d_{5}, 400 \mathrm{MHz}\right): \delta 5.58(1 \mathrm{H}, \mathrm{d}, J=4.3 \mathrm{~Hz}), 5.19$ $(1 \mathrm{H}, \mathrm{d}, J=5.9 \mathrm{~Hz}), 4.77(1 \mathrm{H}, \mathrm{d}, J=5.9 \mathrm{~Hz}), 1.72(3 \mathrm{H}, \mathrm{s}), 1.65(3 \mathrm{H}, \mathrm{d}, J=6.6 \mathrm{~Hz}), 1.65(3 \mathrm{H}, \mathrm{s}), 1.37(3 \mathrm{H}, \mathrm{s})$, $1.33(3 \mathrm{H}, \mathrm{s}), 1.16(3 \mathrm{H}, \mathrm{s}), 0.81(6 \mathrm{H}, \mathrm{d}, J=5.3 \mathrm{~Hz})$ (Figure $\mathrm{S} 1) .{ }^{13} \mathrm{C}$ NMR (pyridine- $\left.d_{5}, 100 \mathrm{MHz}\right): \delta 174.7$ (C-18), 154.1 (C-9), 115.5 (C-11), $106.2\left(\mathrm{C}-1 ”^{\prime \prime}\right), 105.7\left(\mathrm{C}-1^{\prime}\right), 89.2(\mathrm{C}-17), 88.8$ (C-3), $87.1(\mathrm{C}-20), 84.0\left(\mathrm{C}-2^{\prime}\right)$, $78.1\left(\mathrm{C}-3^{\prime}\right), 77.8\left(\mathrm{C}-3^{\prime \prime}\right), 77.1\left(\mathrm{C}-4^{\prime \prime}\right), 76.7\left(\mathrm{C}-2^{\prime \prime}\right), 73.5\left(\mathrm{C}-5^{\prime \prime}\right), 71.3(\mathrm{C}-12), 70.8\left(\mathrm{C}-4^{\prime}\right), 66.7\left(\mathrm{C}-5^{\prime}\right), 58.5$ (C-13), 52.8 (C-5), 46.3 (C-14), 40.8 (C-8), 40.1 (C-4), 39.7 (C-10), 38.8 (C-24), 36.6 (C-22), 36.4 (C-1), 35.8 (C-16), 28.3 (C-28), 28.1 (C-25), 27.9 (C-7), 27.1 (C-15), 27.1 (C-2), 22.9 (C-30), 22.6 (C-21), 22.5 (C-27), 22.5 (C-26), 22.2 (C-23), 21.2 (C-6), 20.0 (C-19), 18.6 (C-6"), 16.7 (C-29) (Figure S2).
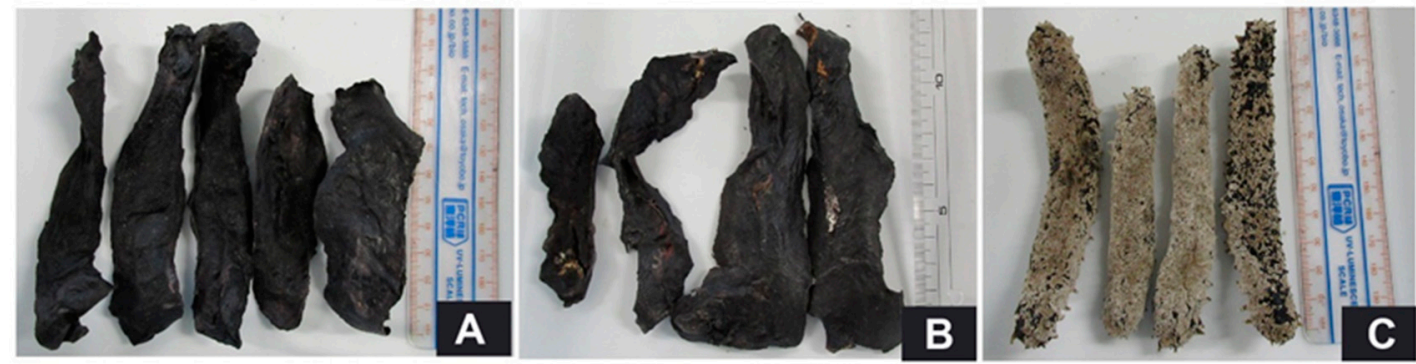

Figure 1. Sea cucumber species after dissection and drying. (A) Holothuria atra; (B) Holothuria leucospilota; (C) Parastichopus nigripunctatus.

\subsection{Phytochemical Characterization of Crude Saponin}

To analyze the major ingredients in crude saponin of $H$. atra, LC/MS analysis was performed on a UFLC XR (Shimadzu, Kyoto, Japan) liquid chromatography system coupled to a Waters Quattro micro API Mass Spectrometer (Waters Corporation, 34 Maple Street, Milford, MA, USA). Samples were analyzed with a flow rate of $0.2 \mathrm{~mL} / \mathrm{min}$ for $40 \mathrm{~min}$ and with the following gradient program: solvent A: $0.1 \%$ formic acid; solvent B: acetonitrile; gradient: 0-3 min 10\% B, 3-30 min 10 to 100\% B, 30-35 min $100 \% \mathrm{~B}, 35.01-40 \mathrm{~min} 10 \% \mathrm{~B}$. The injection volume was $10 \mu \mathrm{L}$. The mass spectra were obtained at a mass-to-charge ratio $(\mathrm{m} / \mathrm{z})$ scan range from 100 to 2000 , and the sample was analyzed in positive ESI mode. Respective MS conditions were as follows: capillary voltage, $4.0 \mathrm{kV}$; source temperature, $120^{\circ} \mathrm{C}$; desolvation temperature, $350{ }^{\circ} \mathrm{C}$; cone gas flow (L/h), 100; desolvation gas flow $(\mathrm{L} / \mathrm{h}), 800$. All data were processed using MassLynx 4.1 software (Waters Corporation, 34 Maple Street, Milford, MA, USA). 


\subsection{Cytotoxicity Assay}

Cells were cultured in the absence and presence of sea cucumber components in variable concentrations, and cytotoxic effects were evaluated through MTT assay [22]. Briefly, seeded cells were incubated with the desired samples for $72 \mathrm{~h}$. Then the supernatant was removed and aliquots of $100 \mu \mathrm{L}$ MTT solution $(0.5 \mathrm{mg} / \mathrm{mL}$ in phosphate buffer saline) were added to each well, and the plate was incubated again at $37^{\circ} \mathrm{C}$ for $3 \mathrm{~h}$. Afterwards, $500 \mu \mathrm{L}$ DMSO (dimethyl sulfoxide) was added to each well, and the plate was shaken for $20 \mathrm{~min}$ to dissolve the formazan crystals. The absorbance was measured spectrophotometrically at $570 \mathrm{~nm}$ wavelength, and the cell viability was calculated from the absorbance of treated versus untreated cells.
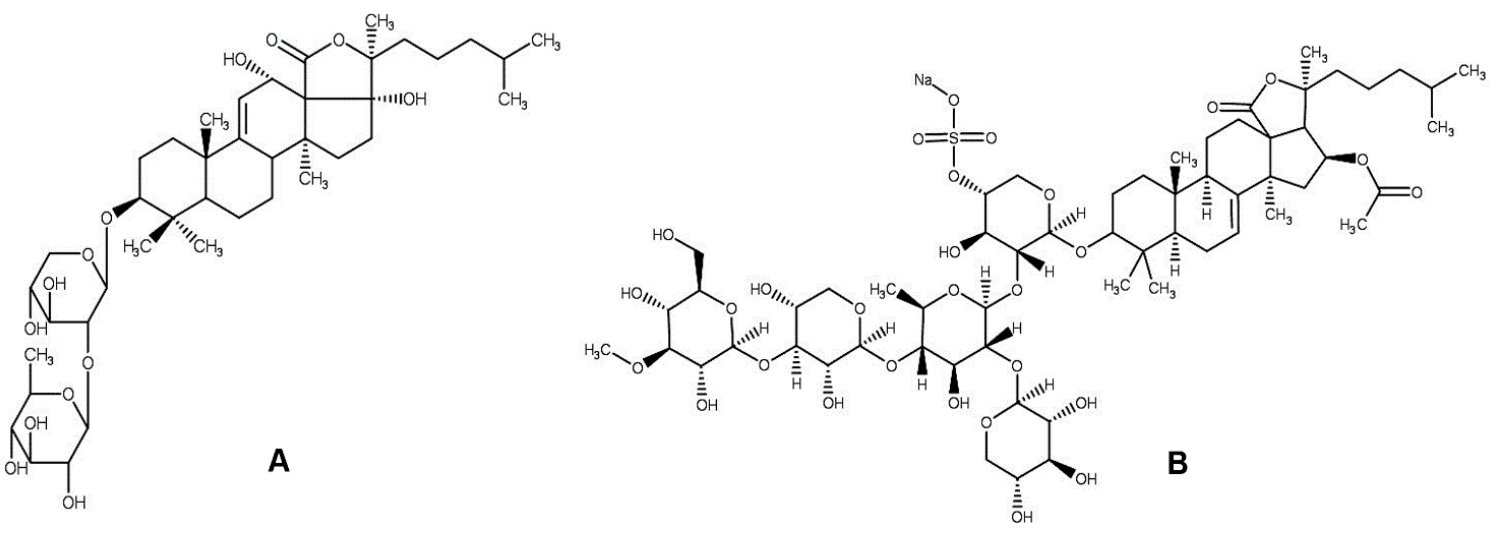

Figure 2. Chemical structure of DEB (desulfated echinoside B) (A) and FRA (frondoside A) (B).

\subsection{In Vivo Cytotoxicity Assay}

The in vivo cytotoxicity of pure saponin was determined using brine shrimps (Artemia salina) [23]. In brief, the desired sample solution $(100 \mu \mathrm{L})$ was added into each well of a 96-well plate, containing 5-10 larvae in artificial seawater $(100 \mu \mathrm{L})$. The plate was incubated at $20^{\circ} \mathrm{C}$ for $24 \mathrm{~h}$. The number of dead larvae in each well was counted using a magnifying lens $(5 \times$ or $10 \times)$. Larvae were considered dead if they did not exhibit any movement. Methanol $(50 \mu \mathrm{L})$ was added to each well and after $1 \mathrm{~h}$ the total number of larvae was counted, and then the toxicity was calculated for each sample.

\subsection{Molecular Docking Simulation}

The three-dimensional (3D) structure of the catalytic domain of PAK1 (PDB Code: 3FXZ) was downloaded from the protein data bank (https:/ / www.rcsb.org/). Then this protein was prepared for docking through removing the heteroatoms with Discovery Studio 4.5 (Accelrys, San Diego, CA, USA). Two dimensional (2D) structures of the ligands were drawn and converted to 3D structures using ChemBio3D Ultra 12.0 (CambridgeSoft, Cambridge, MA, USA). Full optimization of the ligands was carried out via Gaussian 09 (Gaussian, Inc., Wallingford, CT, USA) using the PM6 semi-empirical method. The ligands were saved in pdb format and further used as the input file for molecular docking simulation. AutoDock Vina (The Scripps Research Institute, La Jolla, CA, USA) was used for molecular docking simulation. It is an open source program widely used for molecular docking simulation which significantly improves the accuracy of the binding mode predictions compared to AutoDock 4 [24]. The grid box size was set to maximum to include all the PAK1 catalytic domain, and the dimensions of the grid box were 52.06, 59.09, and $44.73 \AA$ for the $x, y$, and $z$ axes, respectively. The binding pose with the lowest binding affinity was selected as the best pose for the corresponding ligand, and the best pose were further compared with previous studies. The ligand-protein interactions were then visualized and analyzed using PyMol (Schrödinger, Inc., New York, NY, USA) and Discovery Studio 4.5 (Accelrys, San Diego, CA, USA). 


\subsection{Molecular Dynamics (MD) Simulation}

MD simulation was conducted on the docked DEB and FRA complex employing the AMBER14 force field [25] in YASARA dynamics suite [26,27]. The MD system was neutralized by adding $\mathrm{NaCl}$ $(0.9 \%)$ with a $\mathrm{pH}$ of 7.4 . Unless otherwise noted, the temperature of the simulation was set to $298 \mathrm{~K}$. The transferable intermolecular potential3 points (TIP3P) water model was employed and the total water molecules were 4729 with a density of $1.012 \mathrm{gm} / \mathrm{cm}^{3}$. The periodic boundary condition was adopted for performing the simulation, where the box size was $80.5 \times 80.5 \times 80.5 \AA^{3}$. The initial energy minimization process of each simulation system was performed by the simulated annealing method, using the steepest gradient approach (5000 cycles). For measuring the long-range electrostatic interactions, the particle-mesh Ewald approach [28] was used. In addition, for short-range van der Waals and Coulomb interactions, a cut-off radius of $8.0 \AA$ was applied. A multiple time step algorithm together with a simulation time step interval of $2.50 \mathrm{fs}$ was used. At a constant pressure of 1 bar and a temperature of $298 \mathrm{~K}$ using the Berendsen thermostat, the production run was performed for $20 \mathrm{~ns}$ where trajectories were saved at every 100 ps. The MD trajectories were analyzed by a macro program written in YANACONDA language. In this analysis, time, energy, bond distance, bond angle, dihedral angles, columbic and van der Waals interactions, and root mean square deviation (RMSD) values for backbone, alpha carbon, and heavy atoms were collected. To detect the binding affinities after 20 ns MD simulation, ligands were extracted from the simulated complexes and redocked to the corresponding receptor using AutoDock Vina (The Scripps Research Institute, La Jolla, CA, USA) with the same protocol as stated before.

\subsection{Data Analysis}

MTT assays were carried out with 5-6 different treatments having at least 5 replications. Data are represented as $\mathrm{IC}_{50}$ values which were calculated through linear regression analysis.

\section{Results and Discussion}

\subsection{Cytotoxic Effects of Sea Cucumber Components}

Since ancient times, sea cucumbers have been used as a dietary ingredient and traditional medicine, especially in Asian countries. Many recent studies suggest that sea cucumber-derived saponins have significant cytotoxicity on cancer cells through multiple mechanisms including cell cycle progression interference, inducing apoptosis, microtubule stabilization and generation of ceramide [29-31]. This study therefore aimed to identify and purify the cytotoxic saponin from sea cucumber. Three different species were collected and extracted with hot water and $70 \% \mathrm{EtOH}$ separately. Both extracts were investigated for their cytotoxic effects on A549 and B16F10 cells. Irrespective of the extraction methods, $H$. atra showed the highest cytotoxicity, followed by $H$. leucospilota and P. nigiripunctatus (Table 1). Compared to hot water extractions, hydro-alcoholic extractions were found to be more cytotoxic. $70 \%$ EtOH extract of $H$. atra strongly inhibited both A549 and B16F10 cells with $\mathrm{IC}_{50}$ values of 10.5 and $7.9 \mu \mathrm{g} / \mathrm{mL}$, respectively, indicating that this extract could be utilized for further fractionation to purify the active components. Our results were found to be promising compared to a previous study by Dhinakaran and Lipton [32] who reported methanol extract of $H$. atra to be cytotoxic to the Hela and MCF-7 cells with $\mathrm{IC}_{50}$ values 468.0 and $352.0 \mu \mathrm{g} / \mathrm{mL}$, respectively. Next, crude saponin was prepared from hydro-alcoholic extracts of the three species and investigated on cancer cell proliferation. Compared to H. leucospilota and P. nigiripunctatus, H. atra crude saponin induced the highest toxicity on $\mathrm{A} 549$ and B16F10 cells with $\mathrm{IC}_{50}$ values of 1.8 and $0.5 \mu \mathrm{g} / \mathrm{mL}$, respectively (Table 1). These findings demonstrated that cytotoxic effects of sea cucumbers might be due to their saponin contents, and hence, we attempted to purify individual saponin from H. atra crude saponin. 
Table 1. Cytotoxic effects of different sea cucumber extracts/crude saponin.

\begin{tabular}{cccc}
\hline \multirow{2}{*}{ Sea Cucumber Species } & Extracts/Crude Saponin & \multicolumn{2}{c}{ Cytotoxic Effects $\left(\mathbf{I C}_{\mathbf{5 0}}\right.$ Value, $\left.\boldsymbol{\mu g} / \mathbf{m L}\right)$} \\
\cline { 3 - 4 } & & A549 & B16F10 \\
\hline \multirow{3}{*}{ H. atra } & 70\% EtOH Extract & 10.5 & 7.9 \\
& Hot Water Extract & 20.9 & 85.0 \\
& Crude Saponin & 1.8 & 0.5 \\
\hline \multirow{2}{*}{ H. leucospilota } & 70\% EtOH Extract & 15.9 & 9.5 \\
& Hot Water Extract & 28.5 & 125.3 \\
& Crude Saponin & 3.7 & 1.4 \\
\hline \multirow{3}{*}{ P. nigripunctatus } & 70\% EtOH Extract & 36.9 & 8.0 \\
& Hot Water Extract & 26.5 & - \\
& Crude Saponin & 11.5 & 3.3 \\
\hline
\end{tabular}

"-" no cytotoxicity was observed up to $400 \mu \mathrm{g} / \mathrm{mL}$ concentration.

Through HPLC, five fractions (Fr 1-Fr 5) were prepared from $H$. atra crude saponin and tested on A549 and B16F10 cells (Table 2). Fr 2 showed the maximum cytotoxicity ( $\mathrm{IC}_{50}$ values 0.72 and $0.24 \mu \mathrm{g} / \mathrm{mL}$, respectively) followed by $\operatorname{Fr} 4$ ( $\mathrm{IC}_{50}$ values 1.34 and $0.50 \mu \mathrm{g} / \mathrm{mL}$, respectively). Fr 4 was identified as a pure saponin DEB via spectroscopic evidence. To the best of our knowledge, this is the first report of purifying DEB from natural source. DEB was tested for cytotoxicity on cancer cells, and its effects were compared to another active saponin FRA (Figure 2B). DEB showed cytotoxic effects on different cancer cell lines similar to those of FRA. In the case of A549 and B16F10 cells, however, DEB induced more cytotoxicity than FRA with $\mathrm{IC}_{50}$ values of 1.5 and $0.5 \mu \mathrm{M}$, respectively (Table 3). The cytotoxicity of DEB was also confirmed through in vivo assay with brine shrimps [33]. It was also found to be more toxic to the brine shrimps than FRA, and the $\mathrm{IC}_{50}$ value was $9.2 \mu \mathrm{M}$. These findings together confirm the anti-cancer potential of $H$. atra and the future prospect of DEB in chemotherapeutic drug development research.

Table 2. Cytotoxic effects of different fractions of $H$. atra crude saponin.

\begin{tabular}{ccc}
\hline \multirow{2}{*}{ Fractions } & \multicolumn{2}{c}{ Cytotoxic Effects $\left(\mathrm{IC}_{\mathbf{5 0}}\right.$ Value, $\left.\boldsymbol{\mu g} / \mathrm{mL}\right)$} \\
\cline { 2 - 3 } & $\mathbf{A 5 4 9}$ & $\mathbf{B 1 6 F 1 0}$ \\
\hline Fr 1 & 1.35 & 0.60 \\
Fr 2 & 0.72 & 0.24 \\
Fr 3 & 3.40 & 0.90 \\
Fr 4 & 1.34 & 0.50 \\
Fr 5 & 2.38 & 2.42 \\
\hline
\end{tabular}

Table 3. Anti-proliferative effects of desulfated echinoside B and frondoside A.

\begin{tabular}{cccccc}
\hline \multirow{2}{*}{ Compound } & \multicolumn{5}{c}{ Cytotoxic Effects $\left(\mathrm{IC}_{50}\right.$ Value, $\left.\mu \mathrm{M}\right)$} \\
\cline { 2 - 6 } & A549 & B16F10 & HuH-7 & HepG2 & Brine Shrimp \\
\hline $\begin{array}{c}\text { Desulfated } \\
\text { echinoside B }\end{array}$ & 1.5 & 0.5 & 2.5 & 2.1 & 9.2 \\
Frondoside A & 1.6 & 0.6 & 0.4 & 0.6 & 11.5 \\
\hline
\end{tabular}

\subsection{Phytochemical Profile of H. atra Saponin}

LC-ESI-MS analysis was carried out to reveal the phytochemical profile of $H$. atra crude saponin. The sample solution dissolved in methanol was injected into the LC-MS system and analyzed with positive-ion MS scanning. Total ion chromatogram (TIC) was recorded and the corresponding $m / z$ value of the base peak was collected from the source fragmentation (Figure 3). Please check your 
intended meaning is retainedOne aglycone and two saponins were tentatively identified comparing their $m / z$ values to those reported in the literature. The peaks appearing at 15.86, 16.81, and $20.68 \mathrm{~min}$ are holothurinogenin $B$, holothurinoside $K_{1}$, and philinopgenin B, respectively [34-36]. During this investigation, molecular ions with $m / z$ values ranging from $200-800[\mathrm{M}+\mathrm{H}]^{+}$were observed in abundance, indicating the presence of aglycones or saponins with low molecular weight. This analysis only allowed us to identify the known saponins; however, it is necessary to purify individual saponins and then check them using sophisticated spectroscopic techniques for more clarification.

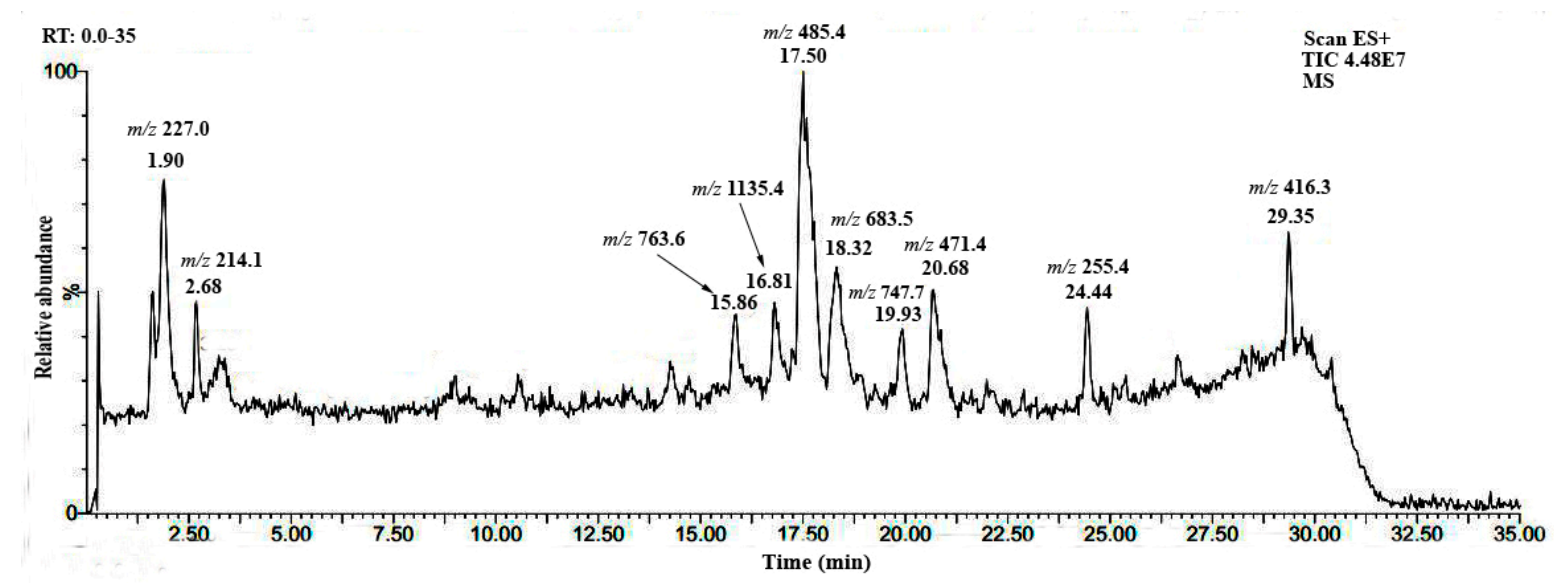

Figure 3. Total ion chromatogram of crude saponin of H. atra showing the mass spectrum (MS) values of major components.

\subsection{Molecular Docking Studies}

Herein, we used molecular docking techniques to explore the binding orientation, affinities, and interaction type of DEB and FRA with the kinase domain of PAK1. All docked compounds were found to bind to the same binding cleft near the hinge region between the C-terminal lobe and the N-terminal lobe (Figure 4). They bind to an allosteric site close to the ATP-binding site, which has been reported to be a novel binding site for allosteric inhibitors (type III kinase inhibitors) [37]. In this study, DEB showed binding free energy of $-8.2 \mathrm{kcal} / \mathrm{mol}$ compared to $-7.7 \mathrm{kcal} / \mathrm{mol}$ for FRA. Both of them showed hydrogen bond interaction with the $\alpha C$ helix residue Glu315 situated in the DFG-out pocket. FRA also interacted with Asp407, a DFG-motif residue, and Thr541, Leu347, Gln278, Arg299, Gly350, Asp354, Thr406 via hydrogen bonds (Table 4). DEB showed more interaction with Arg299 and Tyr346 through hydrogen bond formation. Arg299 was reported to interact with bound ATP in PAK1-KD K299R and with bound FRAX597 in the PAK1 kinase domain [38,39]. DEB and FRA formed one hydrogen bond to the hinge residue Tyr346 and Leu347, respectively, but they did not show hydrogen bond interactions to Glu345 and Leu347 together (Table 4). Glu315 and Leu347 are found in the activation loop and are responsible for the binding of ATP-competitive inhibitors to PAK1 [40]. However, none of the ligands interacted with the gatekeeper residue Met344. These types of interactions are also observed in some other PAK1 crystal structures co-crystallized with different native ligands (4ZLO, 4ZJJ, 4ZJI). In conclusion, both DEB and FRA could be utilized as promising allosteric PAK1 inhibitors and they might also exhibit selective features to the PAK1. Allosteric inhibitors are preferred nowadays due to their selectivity to the kinase, whereas ATP-competitive inhibitors bind to the highly conserved ATP site of all kinases [37]. 


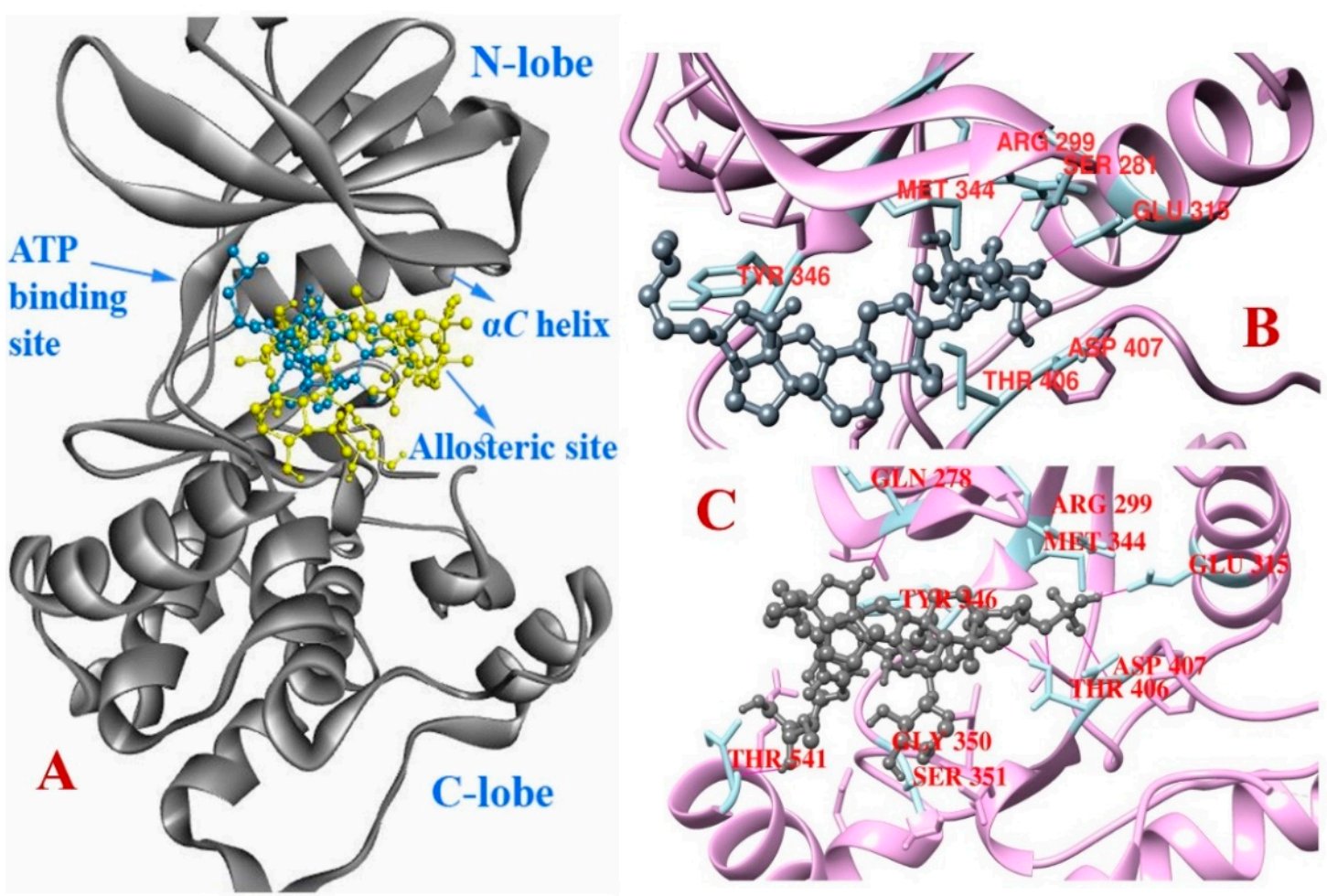

Figure 4. Predicted pose from the docking analysis shows binding orientation of DEB (blue) and FRA (yellow) in the allosteric site of PAK1 (p21-activated kinase 1) kinase domain (A). Non-bonding interactions of DEB and FRA to the allosteric site residues $(\mathbf{B}, \mathbf{C})$. Representative hydrogen bonds between ligand and receptor are shown with lines (pink).

Table 4. Binding affinity and non-bonding interaction of saponins with the catalytic domain of PAK1 obtained using AutoDock vina.

\begin{tabular}{|c|c|c|c|c|c|}
\hline \multirow[b]{2}{*}{ Compound } & \multirow{2}{*}{$\begin{array}{l}\text { Binding } \\
\text { Affinity } \\
\text { (kcal/mol) }\end{array}$} & \multicolumn{2}{|c|}{ Hydrogen Bond Interaction } & \multicolumn{2}{|c|}{ Hydrophobic Interaction } \\
\hline & & $\begin{array}{l}\text { Amino Acid } \\
\text { Residue }\end{array}$ & $\begin{array}{l}\text { Distance } \\
\text { (Å) }\end{array}$ & $\begin{array}{c}\text { Amino Acid } \\
\text { Residue (Bond) }\end{array}$ & $\begin{array}{l}\text { Distance } \\
\text { (̊̊) }\end{array}$ \\
\hline \multirow[t]{5}{*}{ DEB } & -8.2 & Glu315 & 2.17 & Tyr346 (Alkyl-Pi) & 5.34 \\
\hline & & Tyr346 & 2.50 & Leu396 (Alkyl) & 5.37 \\
\hline & & Arg299 & 2.52 & Leu396 (Alkyl) & 4.01 \\
\hline & & Arg299 & 2.17 & Ile276 (Alkyl) & 5.31 \\
\hline & & Thr406 & 2.76 & Tyr346 (Alkyl) & 5.10 \\
\hline \multirow[t]{13}{*}{ FRA } & -7.7 & Lys538 & 2.93 & Tyr346 (Alkyl-Pi) & 5.04 \\
\hline & & Thr541 & 2.08 & Ile276 (Alkyl) & 5.39 \\
\hline & & Leu347 & 2.79 & Ala297 (Alkyl) & 4.23 \\
\hline & & Glu315 & 1.97 & & \\
\hline & & $\mathrm{G} \ln 278$ & 2.07 & & \\
\hline & & Thr406 & 2.28 & & \\
\hline & & Asp407 & 2.00 & & \\
\hline & & Asp354 & 2.21 & & \\
\hline & & Lys538 & 2.76 & & \\
\hline & & Asp354 & 2.66 & & \\
\hline & & Asp354 & 2.75 & & \\
\hline & & Arg299 & 2.57 & & \\
\hline & & Gly350 & 2.88 & & \\
\hline
\end{tabular}




\subsection{Molecular Dynamics}

The molecular docking simulation of DEB and FRA against PAK1 protein is further confirmed by $20 \mathrm{~ns}$ molecular dynamics. The root mean square deviation (RMSD) of backbone atoms in DEB-PAK1 complex revealed that the system becomes stable at around 800 ps and remained within $1.5 \AA$ compared to the docked pose (Figure 5). However, the FRA-PAK1 complex becomes stable after 6 ns and continued to be stable up to $20 \mathrm{~ns}$ at around 2.0 А. Overall, MD simulation further confirmed that both ligands remained within the allosteric binding pocket of PAK1 similar to the docking results (Figure 6). RMSF (root mean square fluctuation) was also analyzed to observe per residue fluctuations throughout the simulation. A large fluctuation was observed in both cases with more than $3.0 \AA$, but most of the residues were found to be stable within $2.0 \AA$ (Figure 5). Importantly, residues (Arg299, Glu315 and so forth) responsible for ligand binding in the allosteric site were found to be slightly less fluctuating (dynamic) in the DEB-PAK1 complex (RMSF: 0.03-0.178 $\AA$ ) compared to those in the FRA-PAK1 complex (RMSF: 0.086-0.213 $\AA$ ). Moreover, DEB and FRA were extracted from the 20 ns MD simulated complexes and redocked with the PAK1 conformer. The binding free energy of $-9.3 \mathrm{kcal} / \mathrm{mol}$ was observed in the DEB-PAK1 complex, compared to $-7.6 \mathrm{kcal} / \mathrm{mol}$ in the FRA-PAK1 complex (Table 5). After 20 ns MD simulation, it was found that DEB forms six hydrogen bonds; among them one bond with $\alpha$ C helix residue Glu315, four bonds with DFG motif residue Asp407, and one bond with Gly277. On the other hand, the number of hydrogen bonds was reduced in MD simulated FRA-PAK1 complex where only three hydrogen bond interactions with Asp354, Thr406, and Tyr346 were observed. Results indicate that DEB could form a more stable complex with PAK1 than FRA, hence DEB might be a potent natural allosteric inhibitor.
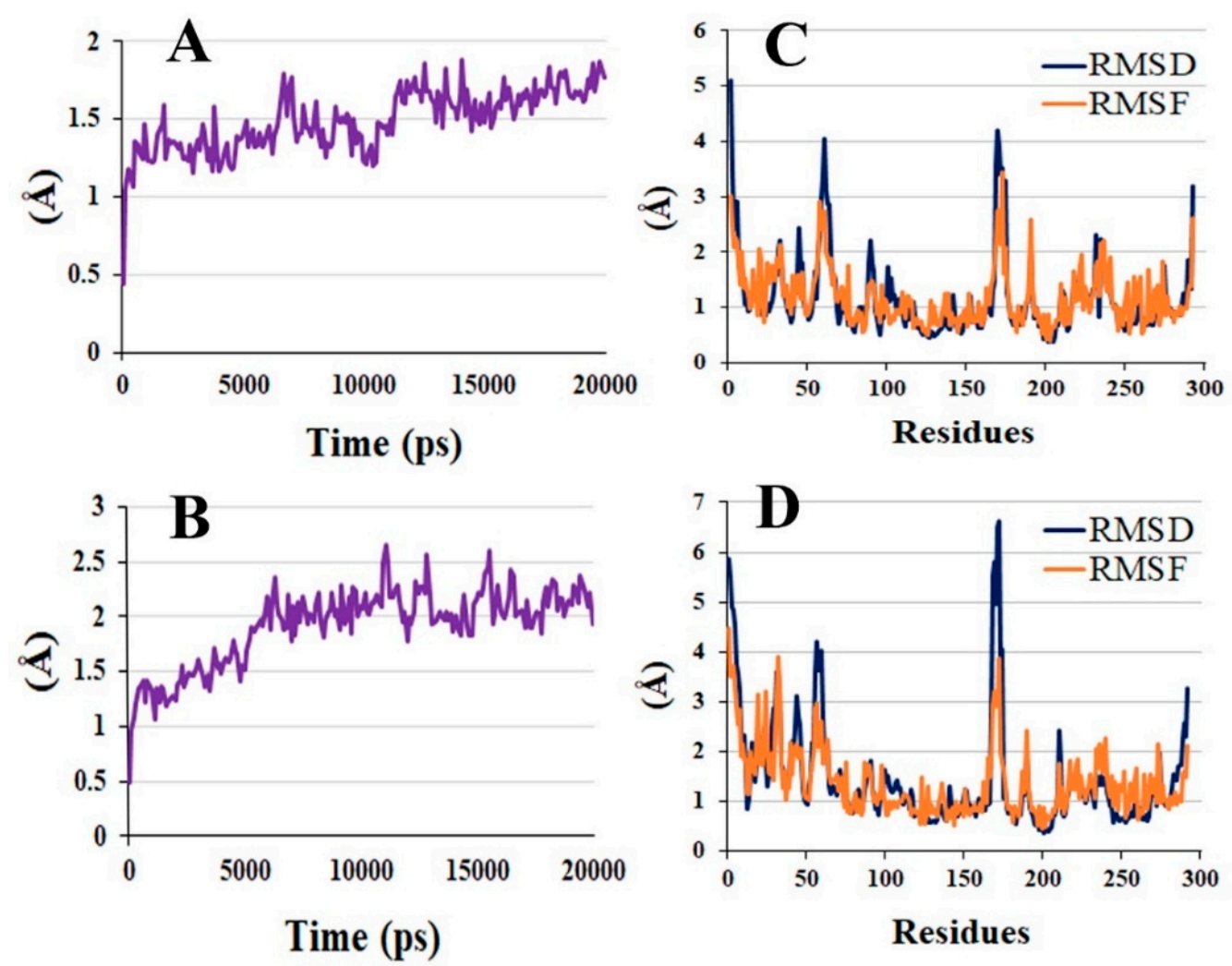

Figure 5. The time series of root mean square deviations of backbone atoms for DEB and FRA complex $(A, B)$. Structural modification of protein by means of root mean square deviations (RMSD) and root mean square fluctuations (RMSF) for DEB and FRA complex (C,D). 


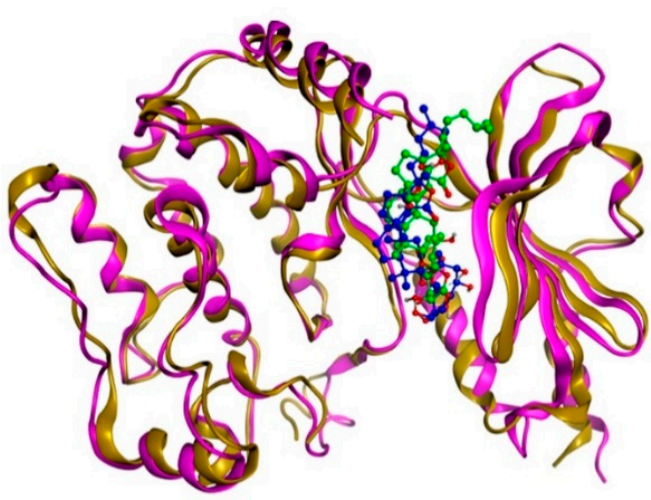

A

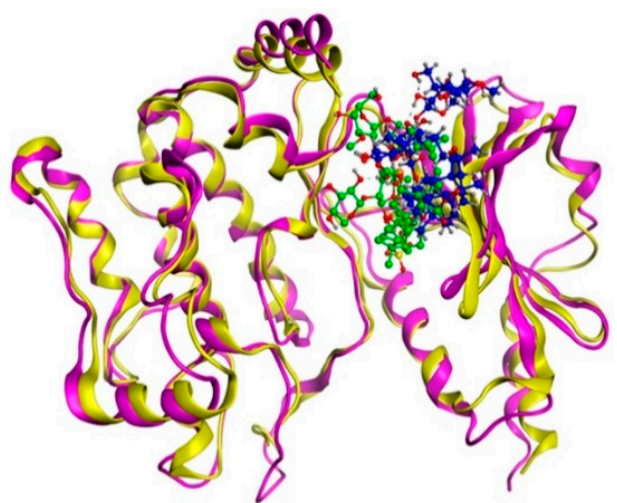

B

Figure 6. Ligand-protein complex poses after $20 \mathrm{~ns}$ molecular dynamics (MD) simulation compared to that of docked complexes. Receptor after molecular docking simulation: yellow; Receptor after 20 ns MD simulation: pink; Ligand after molecular docking simulation: green; Ligand after $20 \mathrm{~ns}$ MD simulation: blue; (A) DEB-PAK1 complex; (B) FRA-PAK1 complex.

Table 5. No-bonding interactions of ligands with the catalytic domain of PAK1 obtained after $20 \mathrm{~ns}$ molecular dynamics simulation.

\begin{tabular}{|c|c|c|c|c|c|c|c|}
\hline \multirow[b]{2}{*}{ Compound } & \multirow{2}{*}{$\begin{array}{l}\text { Binding } \\
\text { Affinity } \\
\text { (kcal/mol) }\end{array}$} & \multicolumn{2}{|c|}{ Hydrogen Bond Interaction } & \multicolumn{2}{|c|}{ Hydrophobic Interaction } & \multicolumn{2}{|c|}{ Electrostatic Interaction } \\
\hline & & $\begin{array}{l}\text { Amino Acid } \\
\text { Residue }\end{array}$ & $\begin{array}{l}\text { Distance } \\
\text { (̊) }\end{array}$ & $\begin{array}{c}\text { Amino Acid } \\
\text { Residue (Bond) }\end{array}$ & $\begin{array}{l}\text { Distance } \\
\text { (Å) }\end{array}$ & $\begin{array}{l}\text { Amino Acid } \\
\text { Residue }\end{array}$ & $\begin{array}{l}\text { Distance } \\
\text { (Å) }\end{array}$ \\
\hline \multirow[t]{6}{*}{ DEB } & -9.3 & Asp407 & 1.63 & Tyr346 (Pi-alkyl) & 5.32 & & \\
\hline & & Glu315 & 1.78 & Leu396 (Alkyl) & 5.24 & & \\
\hline & & Asp407 & 2.72 & Met344 (Alkyl) & 4.65 & & \\
\hline & & Asp407 & 2.40 & Ile276 (Alkyl) & 4.33 & & \\
\hline & & Gly277 & 2.81 & & & & \\
\hline & & Asp407 & 2.35 & & & & \\
\hline \multirow[t]{3}{*}{ FRA } & -7.6 & Asp354 & 1.82 & Tyr346 (Pi-alkyl) & 4.80 & Arg299 & 5.48 \\
\hline & & Thr406 & 1.89 & Ile276 (Alkyl) & 4.93 & & \\
\hline & & Tyr346 & 2.65 & Val284 (Alkyl) & 4.27 & & \\
\hline
\end{tabular}

\section{Conclusions}

In short, the sea cucumber species studied here possess remarkable cytotoxic effects, and among them $H$. atra was found to be the best, irrespective of the extraction method. Their cytotoxic effects may be due to the presence of special saponin ingredients. Phytochemical investigation demonstrated that $H$. atra could be further studied as a rich source of saponins. Desulfated saponin DEB exhibited stronger cytotoxicity on cancer cells and on the brine shrimps than FRA. Molecular docking analysis predicted strong molecular interactions of DEB with the active domain of PAK1, where it binds to the allosteric ligand binding pocket. During MD simulation, DEB showed more stable binding with PAK1 compared to FRA. This study concludes that $H$. atra could be a significant source of cytotoxic saponins, and DEB could be effectively used for chemotherapeutic drug development with more selective inhibitory effects on PAK1 than FRA.

Supplementary Materials: The following are available online at http:/ /www.mdpi.com/2218-0532/86/3/32/s1.

Author Contributions: M.S. carried out the experiments and wrote the draft manuscript; R.T. helped in identification of the purified saponin; M.A.H. (Mohammad A. Halim) performed MD simulation; M.A.H. (Md Amzad Hossain) developed the concept and edited the draft; S.T. and T.I. supervised the whole study and critically reviewed the manuscript.

Funding: This research received no external funding. The APC was funded by Biosystem Consulting Ltd., Co. (Okinawa, Japan). 
Acknowledgments: We are grateful to the fishing company Jinsho, Japan for collecting and supplying the sea cucumber P. nigripunctatus. We also acknowledge the support and laboratory facilities from Biosystem Consulting Ltd., Co. (Okinawa, Japan).

Conflicts of Interest: The authors declare no conflicts of interest.

\section{References}

1. Blunden, G. Biologically active compounds from marine organisms. Phytother. Res. 2001, 15, 89-94. [CrossRef] [PubMed]

2. Guerard, F.; Decourcelle, N.; Sabourin, C.; Floch-laizet, C.; Le Grel, L.; Le Floch, P.; Gourlay, F.; Le Delezir, R.; Jaouen, P.; Bourseau, P. Recent developments of marine ingredients for food and nutraceutical applications: A review. J. Sci. Hal. Aquat. 2011, 2, 21-27.

3. Sarfaraj, H.M.; Sheeba, F.; Saba, A.; Mohd, S. Marine natural products: A lead for Anti-cancer. Indian J. Mar. Sci. 2012, 41, 27-39.

4. Kiew, P.L.; Don, M.M. Jewel of the seabed: Sea cucumbers as nutritional and drug candidates. Int. J. Food Sci. Nutr. 2012, 63, 616-636. [CrossRef] [PubMed]

5. Sugawara, T.; Zaima, N.; Yamamoto, A.; Sakai, S.; Noguchi, R.; Hirata, T. Isolation of sphingoid bases of sea cucumber cerberosides and their cytotoxicity against human colon cancer cells. Biosci. Biotechnol. Biochem. 2006, 70, 2906-2912. [CrossRef] [PubMed]

6. Ridzwan, B.H. Sea Cucumbers, A Malaysian Heritage, 1st ed.; Research Centre of International Islamic University Malaysia (IIUM): Kuala Lumpur Wilayah Persekutuan, Malaysia, 2007; ISBN 9789833855117.

7. Janakiram, N.B.; Mohammed, A.; Rao, C.V. Sea cucumbers metabolites as potent anti-cancer agents. Mar. Drugs. 2015, 13, 2909-2923. [CrossRef] [PubMed]

8. Zou, Z.R.; Yi, Y.H.; Wu, H.M.; Wu, J.H.; Liaw, C.C.; Lee, K.H. Intercedensides A-C, three new cytotoxic triterpene glycosides from the sea cucumber Mensamaria intercedens Lampert. J. Nat. Prod. 2003, 66, 1055-1060. [CrossRef] [PubMed]

9. Tian, F.; Zhang, X.W.; Tong, Y.G.; Yi, Y.H.; Zhang, S.L.; Li, L.; Sun, P.; Lin, L.; Ding, J. PE, a new sulfated saponin from sea cucumber, exhibits anti-angiogenic and anti-tumor activities in vitro and in vivo. Cancer Biol. Ther. 2005, 4, 874-884. [CrossRef] [PubMed]

10. Nguyen, B.C.Q.; Yoshimura, K.; Kumazawa, S.; Tawata, S.; Maruta, H. Frondoside A from sea cucumber and nymphaeols from Okinawa propolis: Natural anti-cancer agents that selectively inhibit PAK1 in vitro. Drug Discov. Ther. 2017, 11, 110-114. [CrossRef] [PubMed]

11. Nguyen, B.C.; Kim, S.A.; Won, S.M.; Park, S.K.; Uto, Y.; Maruta, H. 1, 2, 3-Triazolyl ester of ketorolac (15K): Boosting both heat-endurance and lifespan of C. elegans by down-regulating PAK1 at nM levels. Drug Discov. Ther. 2018, 12, 92-96. [CrossRef] [PubMed]

12. Maruta, H. Herbal therapeutics that block the oncogenic kinase PAK1: A practical approach towards PAK1-dependent diseases and longevity. Phytother. Res. 2014, 28, 656-672. [CrossRef] [PubMed]

13. Maruta, H.; Ahn, M.R. From bench (laboratory) to bed (hospital/home): How to explore effective natural and synthetic PAK1-blockers/longevity-promoters for cancer therapy. Eur. J. Med. Chem. 2017, 142, 229-243. [CrossRef] [PubMed]

14. Razzaghi-Asl, N.; Mirzayi, S.; Mahnam, K.; Sepehri, S. Identification of COX-2 inhibitors via structure-based virtual screening and molecular dynamics simulation. J. Mol. Graph. Model. 2018, 83, 138-152. [CrossRef] [PubMed]

15. Niazi, S.; Purohit, M.; Sonawani, A.; Niazi, J.H. Revealing the molecular interactions of aptamers that specifically bind to the extracellular domain of HER2 cancer biomarker protein: An in silico assessment. J. Mol. Graph. Model. 2018, 83, 112-121. [CrossRef]

16. Mangiaterra, G.; Laudadio, E.; Cometti, M.; Mobbili, G.; Minnelli, C.; Massaccesi, L.; Citterio, B.; Biavasco, F.; Galeazzi, R. Inhibitors of multidrug efflux pumps of Pseudomonas aeruginosa from natural sources: An in silico high-throughput virtual screening and in vitro validation. Med. Chem. Res. 2017, 26, 414-430. [CrossRef]

17. Hu, X.Q.; Wang, Y.M.; Wang, J.F.; Xue, Y.; Li, Z.J.; Nagao, K.; Yanagita, T.; Xue, C.H. Dietary saponins of sea cucumber alleviate orotic acid-induced fatty liver in rats via PPAR $\alpha$ and SREBP-1c signaling. Lipids Health Dis. 2010, 9, 25. [CrossRef] [PubMed] 
18. Baharara, J.; Amini, E.; Nikdel, N.; Salek-Abdollahi, F. The cytotoxicity of dacarbazine potentiated by sea cucumber saponin in resistant B16F10 melanoma cells through apoptosis induction. Avicenna J. Med. Biotechnol. 2016, 8, 112. [PubMed]

19. Moghadam, F.D.; Baharara, J.; Balanezhad, S.Z.; Jalali, M.; Amini, E. Effect of Holothuria leucospilota extracted saponin on maturation of mice oocyte and granulosa cells. Res. Pharm. Sci. 2016, 11, 130. [PubMed]

20. Kitagawa, I.; Kobayashi, M.; Inamoto, T.; Fuchida, M.; Kyogoku, Y. Structures of echinosides A and B, antifungal lanostane-oligosides from the sea cucumber Actinopyga echinites (JAEGER). Chem. Pharm. Bull. 1985, 33, 5214-5224. [CrossRef] [PubMed]

21. Anjaneyulu, A.S.R.; Raju, K.V.S. A new triterpene glycoside from the sea cucumber Holothuria atra off Mandapam Coast. Indian J. Chem. 1996, 35B, 810-814.

22. Ha, Y.M.; Chung, S.W.; Song, S.; Lee, H.; Suh, H.; Chung, H.Y. 4-(6-Hydroxy-2-naphthyl)-1,3-bezendiol: A potent, new tyrosinase inhibitor. Biol. Pharm. Bull. 2007, 30, 1711-1715. [CrossRef] [PubMed]

23. Solis, P.N.; Wright, C.W.; Anderson, M.M.; Gupta, M.P.; Phillipson, J.D. A microwell cytotoxicity assay using Artemia salina (brine shrimp). Planta Med. 1993, 59, 250-252. [CrossRef] [PubMed]

24. Trott, O.; Olson, A.J. AutoDock Vina: Improving the speed and accuracy of docking with a new scoring function, efficient optimization, and multithreading. J. Comput. Chem. 2010, 31, 455-461. [CrossRef] [PubMed]

25. Maier, J.A.; Martinez, C.; Kasavajhala, K.; Wickstrom, L.; Hauser, K.E.; Simmerling, C. ff14SB: Improving the accuracy of protein side chain and backbone parameters from ff99SB. J. Chem. Theory Comput. 2015, 11, 3696-3713. [CrossRef] [PubMed]

26. Krieger, F.; Fierz, B.; Bieri, O.; Drewello, M.; Kiefhaber, T. Dynamics of unfolded polypeptide chains as model for the earliest steps in protein folding. J. Mol. Biol. 2003, 332, 265-274. [CrossRef]

27. Krieger, E.; Darden, T.; Nabuurs, S.B.; Finkelstein, A.; Vriend, G. Making optimal use of empirical energy functions: Force-field parameterization in crystal space. Proteins 2004, 57, 678-683. [CrossRef] [PubMed]

28. Darden, T.; York, D.; Pedersen, L. Particle mesh Ewald: An $N \cdot \log (N)$ method for Ewald sums in large systems. J. Chem. Phys. 1993, 98, 10089-10092. [CrossRef]

29. Kim, S.K.; Himaya, S.W. Triterpene glycosides from sea cucumbers and their biological activities. Adv. Food Nutr. Res. 2012, 65, 297-319. [PubMed]

30. Yun, S.H.; Park, E.S.; Shin, S.W.; Na, Y.W.; Han, J.Y.; Jeong, J.S.; Shastina, V.V.; Stonik, V.A.; Park, J.I.; Kwak, J.Y. Stichoposide $\mathrm{C}$ induces apoptosis through the generation of ceramide in leukemia and colorectal cancer cells and shows in vivo antitumor activity. Clin. Cancer Res. 2012, 18, 5934-5948. [CrossRef] [PubMed]

31. Tian, X.; Tang, H.; Lin, H.; Cheng, G.; Wang, S.; Zhang, X. Saponins: The potential chemotherapeutic agents in pursuing new anti-glioblastoma drugs. Mini Rev. Med. Chem. 2013, 13, 1709-1724. [CrossRef] [PubMed]

32. Dhinakaran, D.I.; Lipton, A.P. Bioactive compounds from Holothuria atra of Indian ocean. SpringerPlus 2014, 3, 673. [CrossRef] [PubMed]

33. Parveen, M.; Ahmad, F.; Malla, A.M.; Azaz, S.; Alam, M.; Basudan, O.A.; Silva, M.R.; Silva, P.S.P. Acetylcholinesterase and cytotoxic activity of chemical constituents of Clutia lanceolata leaves and its molecular docking study. Nat. Prod. Bioprospect. 2016, 6, 267-278. [CrossRef] [PubMed]

34. Van Dyck, S.; Gerbaux, P.; Flammang, P. Qualitative and quantitative saponin contents in five sea cucumbers from the Indian Ocean. Mar. Drugs 2010, 8, 173-189. [CrossRef] [PubMed]

35. Hidalgo, G.V. Comparative Analysis of the Natural Products of Three Sea Cucumber Species: Holothuria grisea, Synaptula reciprocans and Holothuria manningí. Master's Thesis, University of Aberdeen, Aberdeen, Scotland, September 2013.

36. Van Thanh, N.; Dang, N.H.; van Kiem, P.; Cuong, N.X.; Huong, H.T.; van Minh, C. A new triterpene glycoside from the sea cucumber Holothuria scabra collected in Vietnam. ASEAN J. Sci. Technol. Dev. 2017, 23, 253-259. [CrossRef]

37. Karpov, A.S.; Amiri, P.; Bellamacina, C.; Bellance, M.H.; Breitenstein, W.; Daniel, D.; Denay, R.; Fabbro, D.; Fernandez, C.; Galuba, I.; et al. Optimization of a dibenzodiazepine hit to a potent and selective allosteric PAK1 inhibitor. ACS Med. Chem. Lett. 2015, 6, 776-781. [CrossRef] [PubMed]

38. Wang, J.; Wu, J.W.; Wang, Z.X. Structural insights into the autoactivation mechanism of p21-activated protein kinase. Structure 2011, 19, 1752-1761. [CrossRef] [PubMed] 
39. Licciulli, S.; Maksimoska, J.; Zhou, C.; Troutman, S.; Kota, S.; Liu, Q.; Duron, S.; Campbell, D.; Chernoff, J.; Field, J.; et al. FRAX597, a small molecule inhibitor of the p21-activated kinases, inhibits tumorigenesis of neurofibromatosis type 2 (NF2)-associated Schwannomas. J. Biol. Chem. 2013, 288, 29105-29114. [CrossRef] [PubMed]

40. Balupuri, A.; Balasubramanian, P.K.; Cho, S.J. Molecular Docking Studies of p21-Activated Kinase-1 (PAK1) Inhibitors. J. Chosun Nat. Sci. 2016, 9, 161-165. [CrossRef] 